\title{
Involvement of nephrin in human placental trophoblast syncytialization
}

\author{
Yue $\mathrm{Li}^{1,2}$, Ru Zheng ${ }^{2,3}$, Rui Wang ${ }^{2,3}$, Xiaoyin Lü ${ }^{2,3}$, Cheng Zhu ${ }^{2}$, Hai-Yan Lin ${ }^{2}$, Hongmei Wang ${ }^{2}$, \\ Xiaoguang $\mathrm{Yu}^{1}$ and Jiejun $\mathrm{Fu}^{4}$ \\ ${ }^{1}$ Department of Biochemistry and Molecular Biology, College of Basic Medical Science, Harbin Medical University, \\ Harbin 150081, People's Republic of China, ${ }^{2}$ State Key Laboratory of Reproductive Biology, Institute of Zoology, \\ Chinese Academy of Sciences, Beijing 100101, People's Republic of China, ${ }^{3}$ University of Chinese Academy of \\ Sciences, Beijing 100039, People's Republic of China and ${ }^{4}$ Key Laboratory of Longevity and Ageing-related Diseases, \\ Ministry of Education, Guangxi Medical University, Nanning 530021, People's Republic of China
}

Correspondence should be addressed to X Yu; Email: yxg301@163.com or to J Fu; Email: fujiejun@126.com

\begin{abstract}
The placenta has numerous functions, such as transporting oxygen and nutrients and building the immune tolerance of the fetus. Cell fusion is an essential process for placental development and maturation. In human placental development, mononucleated cytotrophoblast (CTB) cells can fuse to form a multinucleated syncytiotrophoblast (STB), which is the outermost layer of the placenta. Nephrin is a transmembrane protein that belongs to the Ig superfamily. Previous studies have shown that nephrin contributes to the fusion of myoblasts into myotubes in zebrafish and mice, presenting a functional conservation with its Drosophila ortholog sticks and stones. However, whether nephrin is involved in trophoblast syncytialization remains unclear. In this study, we report that nephrin was localized predominantly in the CTB cells and STB of human placenta villi from first trimester to term pregnancy. Using a spontaneous fusion model of primary CTB cells, the expression of nephrin was found to be increased during trophoblast cell fusion. Moreover, the spontaneous syncytialization and the expression of syncytin 2, connexin 43, and human chorionic gonadotropin beta were significantly inhibited by nephrin-specific siRNAs. The above results demonstrate that nephrin plays an important role in trophoblast syncytialization.

Reproduction (2015) 149 339-346
\end{abstract}

\section{Introduction}

The syncytialization of trophoblast cells is a key event in human placental morphogenesis. Syncytialization occurs around the time of embryo implantation and continues until delivery. Primary syncytialization is a process in which trophectoderm cells at the embryonic pole of the blastocyst fuse intercellularly and form a multinucleated syncytium that adheres to and penetrates the maternal uterine epithelium; this event is crucial for a successful embryo implantation (Red-Horse et al. 2004). After the blastocyst is fully covered by the maternal uterine epithelium and the placental villi are formed, the syncytiotrophoblast (STB) changes its function and stops invasion. Instead, it develops into the outermost layer of the placental villi, where it directly contacts maternal blood. During the remaining stages of pregnancy, the STB plays important functions in immune tolerance, the production of hormones such as human chorionic gonadotropin beta ( $\beta$-hCG) and the exchange of nutrients and waste products (Malassine \& Cronier 2002, Leisser et al. 2006, Huppertz \& Borges 2008). In the so-called secondary syncytialization, mononucleated cytotrophoblast (CTB) cells lining the placental villi fuse with the multinucleated STB. Fusion and communication between the CTB cells and STB is fundamental for placentation and for a successful pregnancy (Gauster et al. 2010).

Cell fusion appears in a wide variety of organisms and in many cellular processes, such as yeast mating, Caenorhabditis elegans epidermal cell fusion, myotube formation, fertilization, macrophage fusion, tumorigenesis, and placentation (del Campo et al. 2005, Chen \& Olson 2005). A number of proteins have been implicated in the fusion process. Syncytin proteins function as fusogens during trophoblast cell fusion through binding with their receptors (Blond et al. 2000, Mi et al. 2000, Blaise et al. 2003, Esnault et al. 2008). Connexin 43, ADAM12, CD98, and cadherin 11 , all have been demonstrated to play the important roles in trophoblast cell-cell membrane merging (Getsios \& MacCalman 2003, Mori et al. 2004, Dunk et al. 2012). Other factors which are involved in trophoblast cell fusion include proteases (caspases 8, 10, and 14), cytokines (LIF, MIC1, and TNF $\alpha$ ), growth factors (VEGF, CSF, and EGF), and transcription factors (GCM1, Mash-2, and Twist) 
(Yusuf et al. 2002, Baczyk et al. 2009, Butler et al. 2009, Huppertz \& Gauster 2011). Disturbances in syncytial trophoblast differentiation or maintenance may lead to pregnancy disorders such as intrauterine growth restriction and pre-eclampsia. However, the mechanisms governing syncytial fusion remain poorly understood.

Nephrin is the protein product of the NPHS1 gene, which belongs to the Ig superfamily. Nephrin has been found to be highly expressed in the kidney glomerulus (Lenkkeri et al. 1999). As a transmembrane protein, nephrin has a short intracellular domain and a large extracellular domain with eight distal Ig-like motifs (Kestila et al. 1998). Nephrin is a central component of the slit diaphragm in glomerular podocytes (Ruotsalainen et al. 1999). The cell adhesion activities of nephrin have been confirmed in kidney podocytes and HEK-293 cells (Khoshnoodi et al. 2003, George et al. 2012). It is well established that nephrin plays a critical role in the renal ultrafilter. However, little is known about the potential roles of nephrin in extra-renal tissues. Sticks and stones (Sns), the Drosophila ortholog of nephrin, functions as a positive regulator of myoblast fusion and is also required for the adhesion and fusion of insect nephrocytes (Zhuang et al. 2009). Nephrin also has a conserved function in the fusion of zebrafish and mouse myoblasts. Indeed, it has been shown that nephrin mRNA is upregulated in nascent myotubes, and the total amount of myoblast fusion is decreased in nephrin-knockout mice compared with the WTone (Sohn et al. 2009). Therefore, nephrin is critical for the fusion of myoblasts into nascent myotubes (Sohn et al. 2009). So far as we know, there is no report on the expression of nephrin during the fusion of primary human CTB cells and BeWo cells, which are well-characterized models of human placental trophoblast syncytialization. Given its conservative and critical role in myoblast fusion, we hypothesized that nephrin may also play a role in human trophoblast syncytialization.

In this study, we first investigated the expression of nephrin in different human trophoblast cells from first, second, and third trimester placentas. Using a spontaneous syncytialization model of primary CTB cells, we observed increased expression in both nephrin mRNA and protein during the process of syncytialization. Furthermore, the spontaneous syncytialization of primary CTB cells and the expression of syncytin 2, connexin 43, and $\beta$-hCG were significantly inhibited when nephrin was silenced. And the expression of $\beta$-hCG was significantly elevated in nephrin stably overexpressed BeWo cells. The above evidence strongly supports a role for nephrin in human trophoblast syncytialization.

\section{Materials and methods}

\section{Tissue collection}

Human placental villi and term tissues from healthy 27- to 31-year-old women were collected from 301th Hospital of
People's Liberation Army with written consent. Approval to obtain and use these samples for this study was in accordance with the Ethics Committee of the 301th Hospital of People's Liberation Army and the Institute of Zoology at the Chinese Academy of Sciences. For immunohistochemistry and western blotting, nine normal placental tissues at different gestational stages (three from the first trimester, three from the second trimester, and three at term) were used from women who underwent legal abortion or normal delivery. After being washed three times in PBS, the villi were fixed in $4 \%$ paraformaldehyde (PFA) for $24 \mathrm{~h}$ at $4{ }^{\circ} \mathrm{C}$ and kept in $70 \%$ ethyl alcohol until processing.

\section{Isolation of primary CTB cells}

The isolation of CTB cells from human term placentas was performed as described previously (Zhou et al. 2013). The placentas were cut into pieces and digested in DMEM (HyClone, Thermo Scientific, Dubuque, IA, USA) with $0.125 \%$ trypsin (Sigma-Aldrich, Inc.) and 0.02\% DNase I (Sigma) four times. The supernatant was centrifuged for $15 \mathrm{~min}$ at $1200 \mathrm{~g}$ to obtain the cell pellets, which were separated by Percoll (GE Healthcare BioSciences AB, Uppsala, Sweden) density gradient centrifugation. The discontinuous $5-65 \%$ Percoll gradients were made from $3 \mathrm{ml}$ of $90 \%$ Percoll and $1 \times$ HBSS mixtures. CTB cells were purified in a 30-50\% Percoll density gradient. CTB cells were seeded in $35 \mathrm{~mm}$ dishes $\left(2 \times 10^{6} / \mathrm{dish}\right)$ in IMDM (HyClone) with 10\% fetal bovine serum (FBS; Gibco $\mathrm{BRL}), 100 \mathrm{units} / \mathrm{ml}$ penicillin, and $100 \mathrm{units} / \mathrm{ml}$ streptomycin and cultured in a $5 \% \mathrm{CO}_{2}$ air incubator at $37^{\circ} \mathrm{C}$.

\section{BeWo cell culture and fusion assay}

The human choriocarcinoma cell line BeWo was maintained in Ham's F-12K (Kaighn's; Gibco BRL)/DMEM supplemented with $10 \%$ FBS, $100 \mathrm{U} / \mathrm{ml}$ penicillin, and $100 \mathrm{mg} / \mathrm{ml}$ streptomycin in $5 \% \mathrm{CO}_{2} / 95 \%$ air at $37^{\circ} \mathrm{C}$. Cell fusion was induced by treating BeWo cells with forskolin (FSK, Sigma-Aldrich, Inc.) for $48 \mathrm{~h}$. The achievement of cell fusion was assessed by two methods. First, immunofluorescence using anti-human E-cadherin antibody (sc-71008; Santa Cruz Biotechnology) showed the loss of cell membrane during the fusion process. The number of multinucleated cells was counted in five randomly selected areas under the microscope. In addition, whole cell lysates of BeWo cells subjected to cell fusion induction exhibited increased levels of $\beta$-hCG, as shown by western blotting analysis.

\section{Total RNA extraction and real-time PCR}

Total RNA was extracted using TRIzol reagent according to the manufacturer's instructions (Invitrogen). Two micrograms of RNA were reverse transcribed using Superscript II reverse transcriptase (Invitrogen) with oligo (dT) as primers. Real-time PCR was performed by using a SYBR Premix Ex Taq PCR Kit (Takara Biotechnology Co. Ltd, Dalian, China) on an ABI Prism 7500 Real-Time PCR System. Specific primers used were as follows: GAPDH, forward, 5'-AGCCACATCGCTCAGACAC-3' and reverse, 5'-TGGACTCCACGACGTACTC- ${ }^{\prime} ; \beta$-hCG, 
forward, 5'-GAGCTCACCCCAGCATCCTATCACC-3' and reverse, 5'-TTGATGGGGCGGCACCGTGG-3'; and nephrin, forward, 5'-TAGGCAGTTGCTGGTCTGTG-3' and reverse, 5'-GCACTAGGGGGAAAGGTGAC-3'.

\section{Western blotting analysis}

The cells were washed three times with cold PBS and mixed with whole-cell lysis buffer (4 mM EGTA, $3 \mathrm{mM}$ EDTA $\mathrm{pH}$ 8.0, $125 \mathrm{mM} \mathrm{NaF}, 0.5 \mathrm{mM} \mathrm{NA}_{3} \mathrm{VO}_{4}, 2.5 \mu \mathrm{g} / \mathrm{ml}$ aprotinin, $25 \mu \mathrm{g} / \mathrm{ml}$ trypsin inhibitor, $12.5 \mathrm{mM}$ HEPES pH 7.4, 1\% Triton X-100, and $25 \mu \mathrm{M}$ phenylmethylsulphonyl fluoride) as described previously (Zhang et al. 2013). A BCA Protein Assay Kit (Pierce Biotechnology, Thermo Scientific, Dubuque, IA, USA) was used to determine the protein concentration by spectrophotometry at $562 \mathrm{~nm}$ (Beckman DU530, Fullerton, CA, USA). Twenty-five micrograms of each protein sample was subjected to western blotting analysis with the following primary antibodies: rabbit polyclonal anti-nephrin (1:500; ab58968, Abcam, Cambridge, MA, USA), rabbit polyclonal anti-human $\beta$-hCG (1:1000; ab54410, Abcam), mouse monoclonal anti-E-cadherin (1:1000; sc71008, Santa Cruz Biotechnology), mouse monoclonal anti- $\beta$ actin (1:2000; TA-09, Zhongshan Golden Bridge Crop., Beijing, China), rabbit polyclonal anti-syncytin 2 (1:500; AP13018A, Abgent, San Diego, CA, USA), mouse monoclonal anti-connexin 43 (1:1000; 610061, Transduction Laboratories, Lexington, KY, USA), and HRP-conjugated secondary antibodies. Signals were detected by the GeneGnome Imaging System (Syngene Bio-imaging, Cambridge, UK).

\section{Nephrin stable overexpression in BeWo cells}

A full-length human nephrin coding sequence was generated by PCR from a pCMV-SC-CF plasmid (a kind gift from Puneet Garg at University of Michigan School of Medicine, Ann Arbor, MI, USA). Nephrin was cloned into a pGEM-T vector (Promega) and subcloned into a CSII-CMV-MCS-IRES2-Venus vector using the Nhel and Notl sites. The lentivirus vectors were kindly provided by Dr Hiroyuki Miyoshi (Riken BioResource Center, Tsukuba, Japan). All of the lentiviral vectors were generated by transient transfection of 293T cells using the calcium phosphate precipitation method. Briefly, 293T cells were seeded into $100 \mathrm{~mm}$ dishes with DMEM medium containing 10\% FBS. The mixture of the main plasmid and the packaging plasmids was transfected into each dish by calcium phosphate precipitation. The supernatants collected at 48 and $72 \mathrm{~h}$ were concentrated and purified by ultracentrifugation with filter units (Millipore, Schwalbach, Germany), and then the lentivirus was titrated onto HT1080 cells. BeWo cells were infected with nephrin or empty lentivirus and passaged three times to purity by flow cytometry to ensure a transfection rate of more than $95 \%$.

\section{Immunohistochemistry}

Placental tissues from different stages of pregnancy were embedded in paraffin after they were fixed in 4\% PFA, and $5 \mu \mathrm{m}$ sections were cut with a conventional microtome (Leica, Nussloch, Germany). Immunodetection was performed in accordance with the instructions from the biotin-streptavidin-peroxidase and diaminobenzidine kits (Zhongshan Golden Bridge Crop.), as previously reported (Fu et al. 2009). Briefly, slides were boiled in citrate buffer (10 mM citrate sodium, $10 \mathrm{mM}$ citric acid, and $\mathrm{pH}$ 6.0) for $15 \mathrm{~min}$ to retrieve antigen after dewaxing and then were rehydrated. Hydrogen peroxide (3\%) was used to quench endogenous peroxidase activity. After blocking with normal goat serum for $20 \mathrm{~min}$, the slides were incubated overnight at $4{ }^{\circ} \mathrm{C}$ with primary antibodies against nephrin (1:150, ab58968, Abcam), cytokeratin 7 (1:200, ZM-0071, Zhongshan Golden Bridge Crop.) or $\beta$-hCG (1:200, ZM-0134, Zhongshan Golden Bridge Crop.). Purified Igs (IgG) from rabbit or mouse were used as negative controls.

\section{Immunofluorescence}

Primary CTB cells were rinsed in PBS and fixed. After blocking with $5 \%$ donkey serum for $20 \mathrm{~min}$, the slides were incubated with monoclonal anti-E-cadherin (1:100; sc71008, Santa Cruz Biotechnology) overnight at $4{ }^{\circ} \mathrm{C}$ and rinsed in PBS three times for $5 \mathrm{~min}$ each. The cells were then incubated with anti-mouse Alexa Fluor 555 (Invitrogen) secondary antibody for $1 \mathrm{~h}$ at room temperature. The nuclei of the CTB cells were stained with 6'-diamidino-2-phenylindole (DAPI). To quantify primary CTB cells syncytialization without bias, three different nonoverlapping fields were randomly selected for each time point under the microscope. The fusion index was calculated using the format of $(N-S) / T$, where $N$ is the number of nuclei in the syncytia, $S$ is the number of syncytia, and $T$ is the total number of nuclei (Matsuura et al. 2011). All experiments were performed in triplicate and the results are presented as means \pm s.E.M.

\section{RNA interference}

The cells were seeded at $2 \times 10^{6}$ cells into $35 \mathrm{~mm}$ dishes. Onehundred nanomolar nephrin-specific siRNA (Invitrogen; 5'-UGG CUC GGA CCA AAC CAA CAU UCA A-3' and 5'-CUG GGC ACU UGU AUG AUG ATT-3') or negative control siRNA (5'-UUC UCC GAA CGU GUC ACG UTT-3') was diluted in OPTI-MEM and transfected with Lipofectamine 2000 transfection reagent (Invitrogen) according to the manufacturer's recommendations for $6 \mathrm{~h}$. The effect of siRNAs on nephrin levels at $72 \mathrm{~h}$ after transfection was detected by real-time PCR and western blotting.

\section{Statistical analysis}

Each experiment was repeated three times. Data are presented as the mean \pm s.E.M. One-way ANOVA and $t$-tests were used for statistical analyses with $P<0.05$ being considered as significant.

\section{Results}

\section{Expression of nephrin in human placentas at different stages of pregnancy}

To examine the expression of nephrin during human placentation, we carried out immunohistochemistry on placental tissues from the first, second, and third trimesters. CK7, an epithelial marker, was used to 
immunolabel CTB cells, extravillous trophoblast cells in the trophoblast cell column or cells which invaded into the maternal decidua $\left(d\right.$ and $\left.d^{\prime}\right)$, while $\beta$-hCG specifically immunostained the STB layer (c and $c^{\prime}$ ). As shown in Fig. $1 \mathrm{~A}, \mathrm{~B}$ and $\mathrm{C}$, nephrin was highly expressed in both the CTB cells and STB from first to third trimesters $\left(b\right.$ and $\left.b^{\prime}\right)$. Control sections using normal $\operatorname{lgG}$ instead of a primary antibody exhibited no specific staining, as is representatively shown in a and a'.

\section{Validation of spontaneous syncytialization of primary CTB cells}

To elucidate the function of nephrin in placentation under physiological conditions, we first set up a model
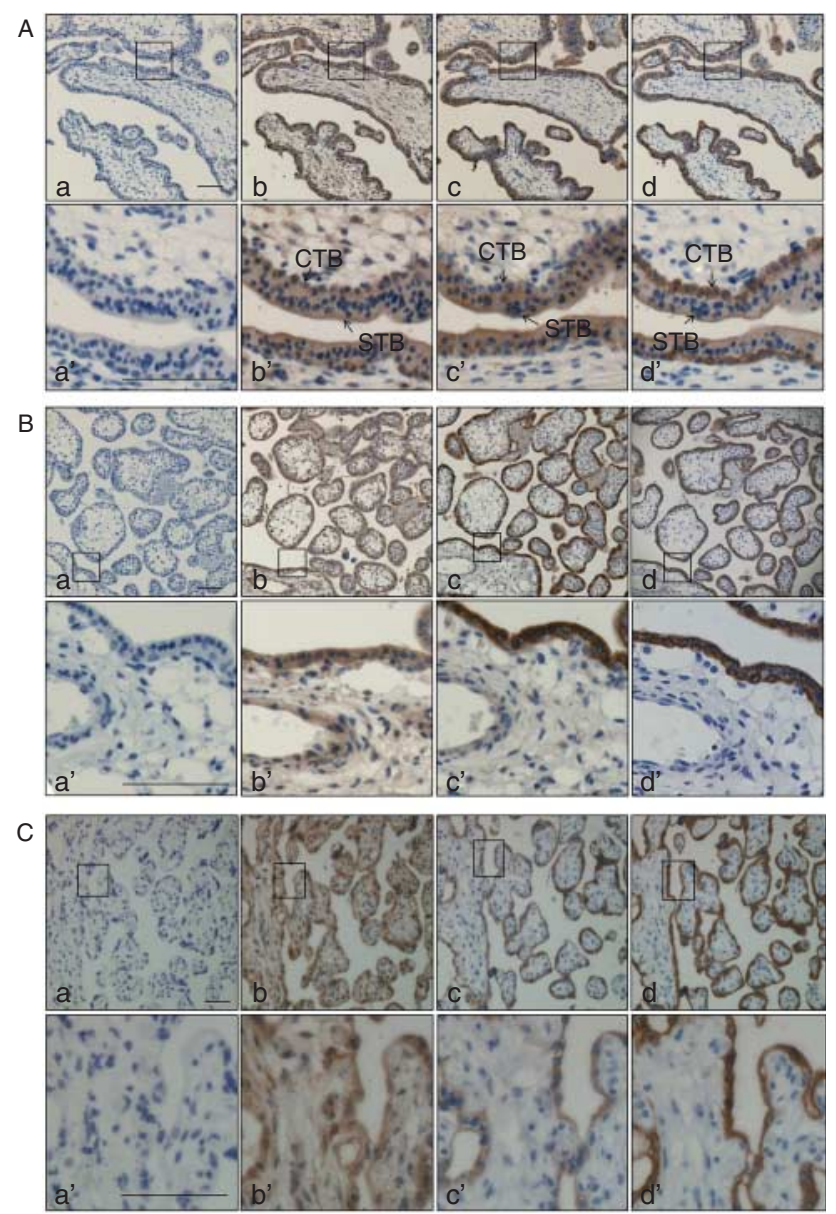

Figure 1 Immunohistochemical localization of nephrin in human placentas at different stages of pregnancy. (A) First-trimester placenta ( $6 \mathrm{~W} ; n=3)$, (B) second-trimester placenta (19 W; $n=3)$, and (C) term placenta (39 W; $n=3$ ). (a and $\mathrm{a}^{\prime}$ ) Negative control images in which normal $\lg G$ is used to replace the primary antibody. ( $b$ and $b^{\prime}$ ) In the placentas of the first and second trimesters $(A$ and $B)$, nephrin is stained in the CTB cells and STB; in the term placenta $(C)$, nephrin is expressed in the presented STB. (c and $\mathrm{c}^{\prime}$ ) $\beta$-hCG immunostaining shows specific signals in the STB. ( $d$ and $\left.d^{\prime}\right)$ Cytokeratin 7 (CK7, an epithelial marker) staining shows CTB cells. CTB, cytotrophoblast cells; STB, syncytiotrophoblast; bar $=100 \mu \mathrm{m}$. for spontaneous syncytialization of primary CTB cells. We isolated fresh CTB cells from human term placenta and obtained a population of cells, more than $95 \%$ of which were CK7-positive (data not shown). We cultured the cells in vitro for $72 \mathrm{~h}$. During this period of time, mononucleated CTB cells spontaneously fused and formed multinucleated syncytia. As shown in Fig. 2A, most cells were mononucleated at $0 \mathrm{~h}$ and showed clear E-cadherin immunostaining on their cell membranes. Some syncytia appeared at a 24-h culture with multiple nuclei in a single cell boundary (arrow). At 48 and $72 \mathrm{~h}$, large syncytia with more than ten nuclei appeared abundantly (arrow). The fusion index was also increased with the process of spontaneous syncytialization (Fig. $2 \mathrm{~B} ; P<0.05$ ); at $72 \mathrm{~h}$ of culture, $\sim 76 \%$ of the cells fused and ended up as multinucleated syncytia. Message levels of $\beta$-hCG were significantly increased (over 1000- and 2000-fold at 48 and $72 \mathrm{~h}$ respectively) during spontaneous fusion of primary cells (Fig. 2C; $P<0.05$ as compared with $0 \mathrm{~h}$ ). Western blotting analysis showed that protein levels of syncytin 2, connexin 43, and $\beta$-hCG were also elevated (Fig. 2D).

\section{Nephrin expression was increased during the spontaneous syncytialization of primary CTB cells}

Next, the expression of nephrin mRNA and protein levels during the syncytialization of primary CTB cells was examined by real-time PCR and western blotting using RNA and protein samples harvested at $0,24,48$, and $72 \mathrm{~h}$ of syncytialization. As shown in Fig. $3 \mathrm{~A}$, the level of nephrin mRNA was low at 0 and $24 \mathrm{~h}$, but was markedly increased at $48 \mathrm{~h}$ and then slightly decreased at $72 \mathrm{~h}$ of culture $(P<0.05$ as compared to $0 \mathrm{~h}$ ). Furthermore, nephrin protein levels showed a similar expression profile (Fig. 3B).

\section{Requirement of nephrin in the fusion of primary CTB cells}

To further assess the function of nephrin in the fusion of primary CTB cells, we used two different siRNAs specifically targeting nephrin to silence the expression in CTB cells. As shown in the Fig. 4A, the level of $\beta$-hCG mRNA was decreased by $\sim 40 \%(P<0.05)$ upon nephrin siRNA1 knockdown. Western blotting analysis showed that the expression levels of syncytin 2, connexin 43, and $\beta$-hCG were decreased when silencing nephrin (Fig. 4B). Immunofluorescence showed that E-cadherin staining disappeared in the negative-control siRNA group (Fig. 4C, left panel), but in the nephrin-silenced group, E-cadherin staining was clearly visible on mononucleated trophoblast cell membranes (Fig. 4C, right panel), and more mononucleated cells were present compared with cells treated with the negative control siRNA. Statistical analysis of the fusion index after nephrin silencing showed that the efficiency of 

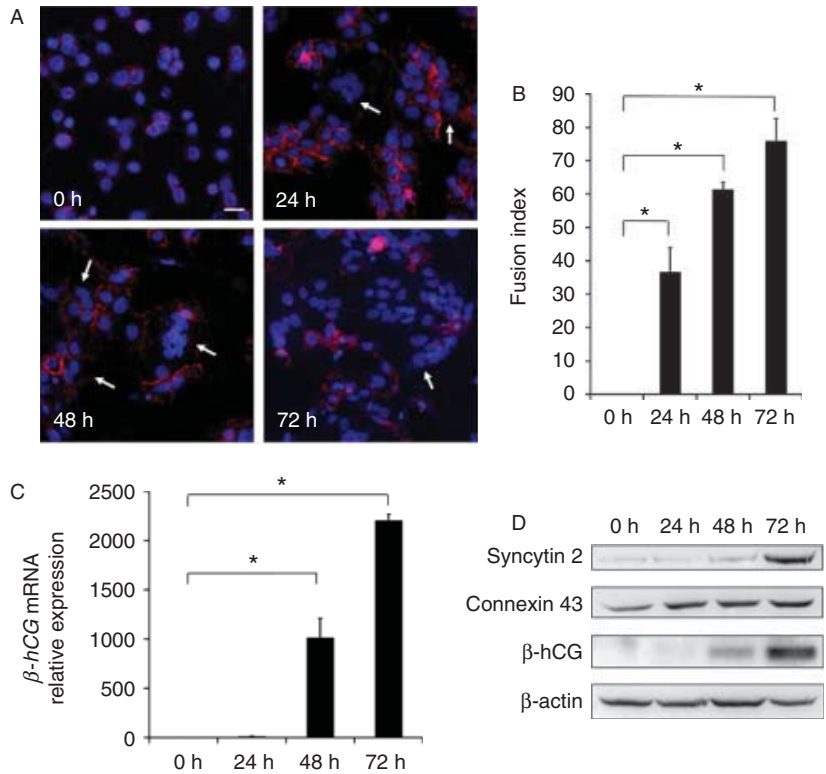

Figure 2 Primary CTB cells from term placenta spontaneously fuse during in vitro culture. (A) Immunofluorescence images show that human primary CTB cells fuse into syncytia in vitro. The nuclei are stained with DAPI. E-cadherin staining (red) shows the cell membrane boundary at $0,24,48$, and $72 \mathrm{~h}$ of in vitro culture. Arrows show syncytium. Bar $=100 \mu \mathrm{m}$. (B) Fusion index of human primary CTB cells syncytialization ( $\left.{ }^{*} P<0.05\right)$. (C) The levels of $\beta$-hCG mRNA are increased during syncytialization of primary CTB cells $(* P<0.05)$. (D) Expression of syncytin 2, connexin 43, and $\beta$-hCG is increased during primary human CTB cells syncytialization $(n=3)$.

syncytialization in the nephrin siRNA group was less than that of the negative control siRNA group (Fig. 4D, $P<0.05)$.

\section{Nephrin overexpression promoted $\beta$-hCG expression in BeWo cells}

To further prove whether there might be a positive relationship between nephrin expression and syncytialization, we constitutively overexpressed nephrin in BeWo cells. Western blotting analysis of the nephrinoverexpressed BeWo cells showed that levels of $\beta$-hCG were increased, as indicated in Fig. 5A and B $(P<0.05)$. Moreover, the fusion index of the nephrin-overexpressed cells was higher than that of the cells transfected with an empty vector (Fig. 5C).

\section{Discussion}

This study suggests that nephrin is involved in trophoblast syncytialization based on the following observations. First, nephrin was expressed in human CTB cells and STB in placentas from the first, second, and third trimesters. Both nephrin mRNA and protein levels were dramatically increased during the spontaneous syncytialization of primary human CTB cells.
Moreover, knockdown of nephrin by siRNA not only reduced the number of syncytia, but also decreased the expression of syncytin 2, connexin 43, and $\beta$-hCG.

Membrane merging is critical for cell-cell fusion. Indeed, the discovery of syncytins is a milestone in the understanding of human syncytialization. The syncytin family includes syncytin 1 and 2 in humans and syncytin A and B in mice (Dupressoir et al. 2005, Lavialle et al. 2013), which are one of the two groups of proteins that are called fusogens in the cell-cell fusion process. The other family of fusogens includes EFF1 and AFF1, which have been discovered in C. elegans (Mohler et al. 2002, del Campo et al. 2005, Sapir et al. 2007). In addition to the above-mentioned fusogens, the expression of connexin 43, a hexamer from which gap junctions are comprised, is increased during the differentiation of CTB cells (Dunk et al. 2012), while the expression of zona occludens- 1 , an adherens junction protein that 'zips' cells together, is predominantly present during CTB cells aggregation but is significantly decreased upon cell fusion (Pidoux et al. 2010). Calponin 3 (CNN3), a CNN family member, is also a negative regulator of trophoblast fusion (Shibukawa et al. 2010). CD98 and its proposed ligand, galectin-3, may play a positive role in promotion of syncytialization (Mori et al. 2004). Our previous studies have shown that the proprotein convertase furin is required for trophoblast

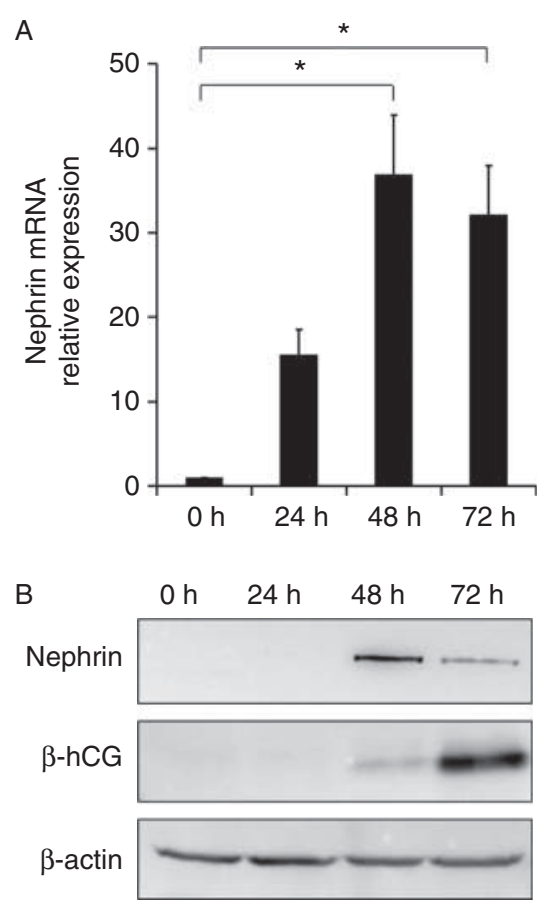

Figure 3 Expression of nephrin during spontaneous syncytialization of primary human CTB cells. (A) Nephrin mRNA is increased in primary human CTB cells spontaneous syncytialization, especially at $48 \mathrm{~h}$ $\left(n=3 ;{ }^{*} P<0.05\right)$. (B) Expression of nephrin protein is increased during syncytialization of primary human CTB cells $(n=3)$. 


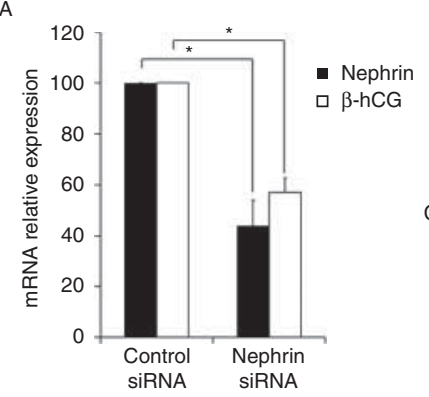

B

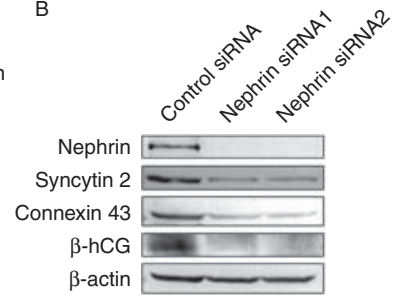

C
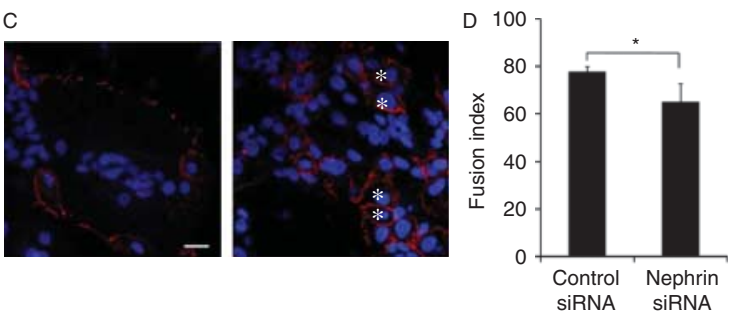

Figure 4 Silencing nephrin inhibits syncytialization in primary CTB cells. Primary human CTB cells were transfected with negative control siRNA or nephrin siRNA1 or $2(n=3)$. (A) Approximately $60 \%$ of nephrin mRNA is knocked down by siRNA1 $\left(n=3 ;{ }^{*} P<0.05\right)$.

(B) Expression of syncytin 2, connexin 43, and $\beta$-hCG is significantly downregulated after nephrin knockdown. (C) Immunofluorescence images of primary human CTB cells transfected with nephrin siRNA (right) or negative control siRNA (left). More mononucleated cells appear in the nephrin siRNA-transfected group compared with the negative control siRNA group (*mononucleated cell). (D) Bar graph of the fusion index after silencing nephrin $\left({ }^{*} P<0.05\right)$.

syncytialization, and the expression of furin in the STB is significantly lower in placentas from pre-eclampsia patients (Zhou et al. 2013). In addition, the processing of insulin-like growth factor 1 receptor (IGF1R) by furin is necessary for trophoblast syncytialization (Zhou et al. 2013). E-cadherin levels are significantly increased during earlier stages of syncytialization (Coutifaris et al. 1991). However, as syncytialization progresses, for example, $\sim 24 \mathrm{~h}$ later in culture in the spontaneous syncytialization system, E-cadherin levels are decreased (Coutifaris et al. 1991). In contrast, cadherin-11 expression increases during the formation of multinucleated syncytia, and it promotes the morphological and functional differentiation of human CTB cells (Getsios \& MacCalman 2003).

The expression of nephrin has been found in the kidney, pancreas, brain, and lymphoid tissues (Putaala et al. 2001, Astrom et al. 2006). Verma et al. (2006) have observed that mutation or deletion of nephrin protein in the slit diaphragm in the kidney leads to a defect in podocyte foot process morphogenesis, and that proteinuria is the clinical symptom. Sohn et al. (2009) have confirmed that nephrin knockout myoblasts fuse less efficiently into nascent human myotubes, and downregulation of nephrin expression results in muscle defects in zebrafish and mice. Interestingly, nephrin interacts with $\mathrm{SH} 2-\mathrm{SH} 3$ domain-containing adapter Nck to regulate actin cytoskeletal dynamics in podocytes (Verma et al. 2006), and in myoblast fusion, the appearance of actin foci is obligatory for fusion (Onel \& Renkawitz-Pohl 2009, Haralalka et al. 2011). Coexpression of Sns and EFF1 can induce highly efficient cell fusion in Drosophila S2R + cells (Shilagardi et al. 2013). Our study adds a new function for nephrin during primary trophoblast syncytialization, which is accompanied by the increase in important fusion-related molecules, including syncytin 2 , connexin 43 , and $\beta$-hCG. When the expression of nephrin was knocked down, trophoblast syncytialization as well as the expression of syncytin 2 and connexin 43 was decreased. In the placenta, syncytin is located on the cell membrane and mediates placental CTB cell fusion by binding to the syncytin receptor (Mi et al. 2000, Esnault et al. 2008, Huppertz \& Borges 2008, Vargas et al. 2009). As a gap junctional protein, connexin 43 is required for CTB cell fusion into syncytia (Dunk et al. 2012, Pidoux et al. 2014). We therefore speculate that nephrin may be involved in the syncytialization machinery via enhancing the expression of syncytin and connexin 43 , and the underlying mechanisms await further study.

Aberrant fusion of the CTB cells with the STB will impair the maintenance and integrity of the placental barrier, which may thus be involved in pregnancy disorders. Interestingly, it has been reported that serum and urine concentrations of nephrin are associated with pre-eclampsia and small for gestational age infants (Yang et al. 2013). Therefore, nephrin may play a role in the pathogenesis of proteinuria in pre-eclampsia. Further investigation is necessary for elucidating the clinical
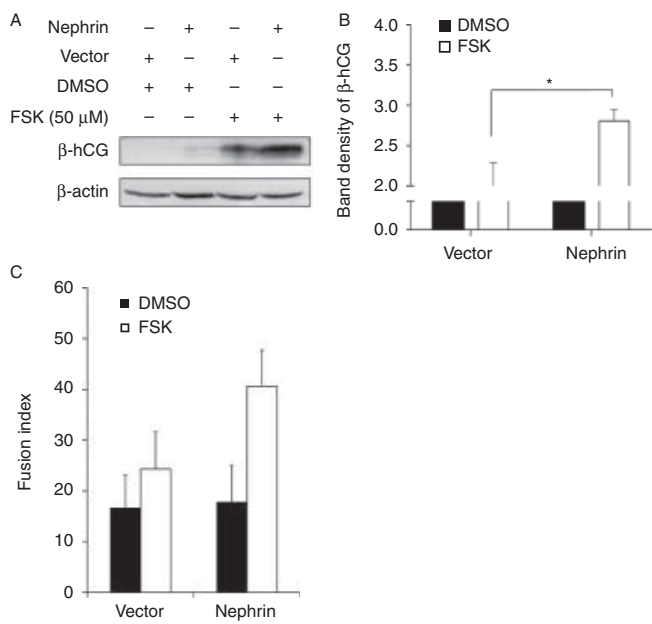

Figure 5 Nephrin overexpression promotes $\beta$-hCG expression in BeWo cells. Nephrin stably overexpressed BeWo cells and control BeWo cells were incubated in a medium with or without $50 \mu \mathrm{M}$ FSK for $48 \mathrm{~h}$. (A) Western blotting analysis shows that levels of $\beta$-hCG protein are increased in nephrin overexpressed cells compared with control cells. (B) Bar graph of $\beta$-hCG band density $\left({ }^{*} P<0.05\right)$. (C) Bar graph of the fusion index after nephrin overexpression in BeWo cells. 
significance of placental nephrin in pregnancy-related diseases. Taken together, we herein demonstrate a new function for nephrin in promoting the syncytialization of human trophoblast cells.

\section{Declaration of interest}

The authors declare that there is no conflict of interest that could be perceived as prejudicing the impartiality of the research reported.

\section{Funding}

This study was supported by National Natural Science Foundation of China (grant number 81201669).

\section{References}

Astrom E, Rinta-Valkama J, Gyling M, Ahola H, Miettinen A, Timonen T \& Holthofer H 2006 Nephrin in human lymphoid tissues. Cellular and Molecular Life Sciences 63 498-504. (doi:10.1007/s00018-0055498-0)

Baczyk D, Drewlo S, Proctor L, Dunk C, Lye S \& Kingdom J 2009 Glial cell missing-1 transcription factor is required for the differentiation of the human trophoblast. Cell Death and Differentiation 16 719-727. (doi:10.1038/cdd.2009.1)

Blaise S, de Parseval N, Benit L \& Heidmann T 2003 Genomewide screening for fusogenic human endogenous retrovirus envelopes identifies syncytin 2, a gene conserved on primate evolution. PNAS 100 13013-13018. (doi:10.1073/pnas.2132646100)

Blond JL, Lavillette D, Cheynet V, Bouton O, Oriol G, Chapel-Fernandes S, Mandrand B, Mallet F \& Cosset FL 2000 An envelope glycoprotein of the human endogenous retrovirus HERV-W is expressed in the human placenta and fuses cells expressing the type D mammalian retrovirus receptor. Journal of Virology 74 3321-3329. (doi:10.1128/JVI.74.7. 3321-3329.2000)

Butler TM, Elustondo PA, Hannigan GE \& MacPhee DJ 2009 Integrin-linked kinase can facilitate syncytialization and hormonal differentiation of the human trophoblast-derived BeWo cell line. Reproductive Biology and Endocrinology 7 51. (doi:10.1186/1477-7827-7-51)

del Campo JJ, Opoku-Serebuoh E, Isaacson AB, Scranton VL, Tucker M, Han M \& Mohler WA 2005 Fusogenic activity of EFF-1 is regulated via dynamic localization in fusing somatic cells of $C$. elegans. Current Biology 15 413-423. (doi:10.1016/j.cub.2005.01.054)

Chen EH \& Olson EN 2005 Unveiling the mechanisms of cell-cell fusion. Science 308 369-373. (doi:10.1126/science.1104799)

Coutifaris C, Kao LC, Sehdev HM, Chin U, Babalola GO, Blaschuk OW \& Strauss JF III 1991 E-cadherin expression during the differentiation of human trophoblasts. Development 113 767-777.

Dunk CE, Gellhaus A, Drewlo S, Baczyk D, Potgens AJ, Winterhager E, Kingdom JC \& Lye SJ 2012 The molecular role of connexin 43 in human trophoblast cell fusion. Biology of Reproduction 86 115. (doi:10.1095/ biolreprod.111.096925)

Dupressoir A, Marceau G, Vernochet C, Benit L, Kanellopoulos C, Sapin V \& Heidmann T 2005 Syncytin-A and syncytin-B, two fusogenic placentaspecific murine envelope genes of retroviral origin conserved in Muridae. PNAS 102 725-730. (doi:10.1073/pnas.0406509102)

Esnault C, Priet S, Ribet D, Vernochet C, Bruls T, Lavialle C, Weissenbach J \& Heidmann T 2008 A placenta-specific receptor for the fusogenic, endogenous retrovirus-derived, human syncytin-2. PNAS 105 17532-17537. (doi:10.1073/pnas.0807413105)

Fu JJ, Lin P, Lv XY, Yan XJ, Wang HX, Zhu C, Tsang BK, Yu XG \& Wang H 2009 Low molecular mass polypeptide-2 in human trophoblast: over-expression in hydatidiform moles and possible role in trophoblast cell invasion. Placenta 30 305-312. (doi:10.1016/j. placenta.2009.01.005)
Gauster M, Siwetz M, Orendi K, Moser G, Desoye G \& Huppertz B 2010 Caspases rather than calpains mediate remodelling of the fodrin skeleton during human placental trophoblast fusion. Cell Death and Differentiation 17 336-345. (doi:10.1038/cdd.2009.133)

George B, Verma R, Soofi AA, Garg P, Zhang J, Park TJ, Giardino L, Ryzhova L, Johnstone DB, Wong H et al. 2012 Crk1/2-dependent signaling is necessary for podocyte foot process spreading in mouse models of glomerular disease. Journal of Clinical Investigation 122 674-692. (doi:10.1172/JCl60070)

Getsios S \& MacCalman CD 2003 Cadherin-11 modulates the terminal differentiation and fusion of human trophoblastic cells in vitro. Developmental Biology 257 41-54. (doi:10.1016/S0012-1606(03)00041-1)

Haralalka S, Shelton C, Cartwright HN, Katzfey E, Janzen E \& Abmayr SM 2011 Asymmetric Mbc, active Rac1 and F-actin foci in the fusioncompetent myoblasts during myoblast fusion in Drosophila. Development 138 1551-1562. (doi:10.1242/dev.057653)

Huppertz B \& Borges M 2008 Placenta trophoblast fusion. Methods in Molecular Biology 475 135-147. (doi:10.1007/978-1-59745-250-2_8)

Huppertz B \& Gauster M 2011 Trophoblast fusion. Advances in Experimental Medicine and Biology 713 81-95. (doi:10.1007/978-94007-0763-4_6)

Kestila M, Lenkkeri U, Mannikko M, Lamerdin J, McCready P, Putaala $\mathbf{H}_{\text {, }}$ Ruotsalainen V, Morita T, Nissinen M, Herva R et al. 1998 Positionally cloned gene for a novel glomerular protein - nephrin - is mutated in congenital nephrotic syndrome. Molecular Cell 1 575-582. (doi:10. 1016/S1097-2765(00)80057-X)

Khoshnoodi J, Sigmundsson K, Ofverstedt LG, Skoglund U, Obrink B, Wartiovaara J \& Tryggvason K 2003 Nephrin promotes cell-cell adhesion through homophilic interactions. American Journal of Pathology 163 2337-2346. (doi:10.1016/S0002-9440(10)63590-0)

Lavialle C, Cornelis G, Dupressoir A, Esnault C, Heidmann O, Vernochet C \& Heidmann T 2013 Paleovirology of 'syncytins', retroviral env genes exapted for a role in placentation. Philosophical Transactions of the Royal Society of London. Series B, Biological Sciences 36820120507. (doi:10.1098/rstb.2012.0507)

Leisser C, Saleh L, Haider S, Husslein H, Sonderegger S \& Knofler M 2006 Tumour necrosis factor-alpha impairs chorionic gonadotrophin betasubunit expression and cell fusion of human villous cytotrophoblast. Molecular Human Reproduction 12 601-609. (doi:10.1093/molehr/ gal066)

Lenkkeri U, Mannikko M, McCready P, Lamerdin J, Gribouval O, Niaudet PM, Antignac CK, Kashtan CE, Homberg C, Olsen A et al. 1999 Structure of the gene for congenital nephrotic syndrome of the finnish type (NPHS1) and characterization of mutations. American Journal of Human Genetics 64 51-61. (doi:10.1086/302182)

Malassine A \& Cronier L 2002 Hormones and human trophoblast differentiation: a review. Endocrine 193-11. (doi:10.1385/ENDO:19:1:3)

Matsuura K, Jigami T, Taniue K, Morishita Y, Adachi S, Senda T, Nonaka A, Aburatani H, Nakamura T \& Akiyama T 2011 Identification of a link between $\mathrm{Wnt} / \beta$-catenin signalling and the cell fusion pathway. Nature Communications 2 548. (doi:10.1038/ncomms1551)

Mi S, Lee X, Li X, Veldman GM, Finnerty H, Racie L, LaVallie E, Tang XY, Edouard P, Howes S et al. 2000 Syncytin is a captive retroviral envelope protein involved in human placental morphogenesis. Nature $\mathbf{4 0 3}$ 785-789. (doi:10.1038/35001608)

Mohler WA, Shemer G, del Campo JJ, Valansi C, Opoku-Serebuoh E, Scranton V, Assaf N, White JG \& Podbilewicz B 2002 The type I membrane protein EFF-1 is essential for developmental cell fusion. Developmental Cell 2 355-362. (doi:10.1016/S1534-5807(02)00129-6)

Mori K, Nishimura $M$, Tsurudome $M$, Ito $M$, Nishio $M$, Kawano $M$, Kozuka Y, Yamashita Y, Komada H, Uchida A et al. 2004 The functional interaction between CD98 and CD147 in regulation of virus-induced cell fusion and osteoclast formation. Medical Microbiology and Immunology 193 155-162. (doi:10.1007/s00430-003-0191-0)

Onel SF \& Renkawitz-Pohl R 2009 FuRMAS: triggering myoblast fusion in Drosophila. Developmental Dynamics 238 1513-1525. (doi:10.1002/ dvdy.21961)

Pidoux G, Gerbaud P, Gnidehou S, Grynberg M, Geneau G, Guibourdenche J, Carette D, Cronier L, Evain-Brion D, Malassine A et al. 2010 ZO-1 is involved in trophoblastic cell differentiation in human placenta. American Journal of Physiology. Cell Physiology 298 C1517-C1526. (doi:10.1152/ajpcell.00484.2008) 
Pidoux G, Gerbaud P, Dompierre J, Lygren B, Solstad T, Evain-Brion D \& Tasken K 2014 A PKA-ezrin-connexin 43 signaling complex controls gap junction communication and thereby trophoblast cell fusion. Journal of Cell Science 127 4172-4185. (doi:10.1242/jcs. 149609)

Putaala H, Soininen R, Kilpelainen P, Wartiovaara J \& Tryggvason K 2001 The murine nephrin gene is specifically expressed in kidney, brain and pancreas: inactivation of the gene leads to massive proteinuria and neonatal death. Human Molecular Genetics 10 1-8. (doi:10.1093/hmg/ 10.1.1)

Red-Horse K, Zhou Y, Genbacev O, Prakobphol A, Foulk R, McMaster M \& Fisher SJ 2004 Trophoblast differentiation during embryo implantation and formation of the maternal-fetal interface. Journal of Clinical Investigation 114 744-754. (doi:10.1172/JCl200422991)

Ruotsalainen V, Ljungberg $P$, Wartiovaara J, Lenkkeri U, Kestila $M$, Jalanko H, Holmberg C \& Tryggvason K 1999 Nephrin is specifically located at the slit diaphragm of glomerular podocytes. PNAS $\mathbf{9 6}$ 7962-7967. (doi:10.1073/pnas.96.14.7962)

Sapir A, Choi J, Leikina E, Avinoam O, Valansi C, Chernomordik LV, Newman AP \& Podbilewicz B 2007 AFF-1, a FOS-1-regulated fusogen, mediates fusion of the anchor cell in C. elegans. Developmental Cell 12 683-698. (doi:10.1016/j.devcel.2007.03.003)

Shibukawa Y, Yamazaki N, Kumasawa K, Daimon E, Tajiri M, Okada Y, Ikawa M \& Wada Y 2010 Calponin 3 regulates actin cytoskeleton rearrangement in trophoblastic cell fusion. Molecular Biology of the Cell 21 3973-3984. (doi:10.1091/mbc.E10-03-0261)

Shilagardi K, Li S, Luo F, Marikar F, Duan R, Jin P, Kim JH, Murnen K \& Chen EH 2013 Actin-propelled invasive membrane protrusions promote fusogenic protein engagement during cell-cell fusion. Science $\mathbf{3 4 0}$ 359-363. (doi:10.1126/science.1234781)

Sohn RL, Huang P, Kawahara G, Mitchell M, Guyon J, Kalluri R, Kunkel LM \& Gussoni E 2009 A role for nephrin, a renal protein, in vertebrate skeletal muscle cell fusion. PNAS 106 9274-9279. (doi:10.1073/pnas. 0904398106)
Vargas A, Moreau J, Landry S, LeBellego F, Toufaily C, Rassart E, Lafond J \& Barbeau B 2009 Syncytin-2 plays an important role in the fusion of human trophoblast cells. Journal of Molecular Biology 392 301-318. (doi:10.1016/j.jmb.2009.07.025)

Verma R, Kovari I, Soofi A, Nihalani D, Patrie K \& Holzman LB 2006 Nephrin ectodomain engagement results in Src kinase activation, nephrin phosphorylation, Nck recruitment, and actin polymerization. Journal of Clinical Investigation 116 1346-1359. (doi:10.1172/JCI27414)

Yang GY, Lee KA, Park MH, Park HS, Ha EH, Chun SH \& Kim YJ 2013 Urinary nephrin: a new predictive marker for pregnancies with preeclampsia and small-for-gestational age infants. Obstetrics \& Gynecology Science $\mathbf{5 6}$ 22-28. (doi:10.5468/OGS.2013.56.1.22)

Yusuf K, Smith SD, Sadovsky Y \& Nelson DM 2002 Trophoblast differentiation modulates the activity of caspases in primary cultures of term human trophoblasts. Pediatric Research 52 411-415. (doi:10.1203/ 00006450-200209000-00018)

Zhang Q, Chen Q, Lu X, Zhou Z, Zhang H, Lin HY, Duan E, Zhu C, Tan Y \& Wang H 2013 CUL1 promotes trophoblast cell invasion at the maternalfetal interface. Cell Death \& Disease 4 e502. (doi:10.1038/cddis.2013.1)

Zhou Z, Zhang Q, Lu X, Wang R, Wang H, Wang YL, Zhu C, Lin HY \& Wang H 2013 The proprotein convertase furin is required for trophoblast syncytialization. Cell Death \& Disease 4 e593. (doi:10. 1038/cddis.2013.106)

Zhuang S, Shao H, Guo F, Trimble R, Pearce E \& Abmayr SM 2009 Sns and Kirre, the Drosophila orthologs of Nephrin and Neph1, direct adhesion, fusion and formation of a slit diaphragm-like structure in insect nephrocytes. Development 136 2335-2344. (doi:10.1242/dev.031609)

Received 19 August 2014

First decision 14 September 2014

Revised manuscript received 18 January 2015

Accepted 22 January 2015 